\title{
KELAYAKAN EKONOMI USAHATANI JAGUNG DENGAN KOMBINASI APLIKASI BIOCHAR DAN PUPUK KALIUM
}

\author{
Asnah dan Widowati \\ Fakultas Pertanian Universitas Tribhuwana Tunggadewi \\ Jl. Telaga Warna Tlogomas, Malang Telp/fax 0341-565500/565522 \\ E-mail: asnah@unitri.ac.id dan widwidowati@gmail.com
}

\begin{abstract}
The limited factors to achievement of farming success is the ability of farmers to finance farming. Factros of cost is often limited factor/budget constrain because availability costs affect the ability of farmer to provision of the required factors of production farming. This research aims to study economic viability of maize farming with a combination of biochar application and potash fertilizers.

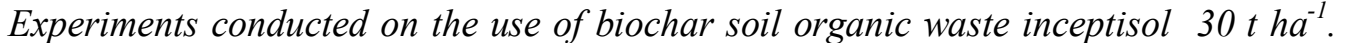
The data collected were tabulated and analyzed by economic analysis of farming. The results showed the combination of biochar application and potash fertilizers $1 / 4$ dose of recommendations (treatment BK 1/4) economically feasible to develop the farmers in term of production $\left(7.02 \mathrm{t} \mathrm{h \textrm {h } ^ { - 1 }}\right)$, revenue $\mathrm{Rp} 19.305 .000 \mathrm{ha}^{-1}$, income $\mathrm{Rp} 8.663 .000$ $h^{-1}$, economic feasibility $(R / C) 1.8$ and the value of labor productivity of $R p$ 48.166/HKO.
\end{abstract}

Keywords : economic feasibility, maize farming, biochar.

\begin{abstract}
Abstrak: Faktor yang sering menjadi kendala dalam pencapaian keberhasilan usahatani adalah kemampuan petani dalam membiayai usahatani. Faktor biaya sering menjadi faktor pembatas (limited factor/budget constrain) dikarenakan ketersediaan biaya mempengaruhi kemampuan petani dalam penyediaan faktor produksi yang dibutuhkan dalam usahatani. Penelitian ini bertujuan untuk mempelajari kelayakan ekonomi usahatani jagung dengan kombinasi aplikasi biochar dan pupuk kalium. Percobaan dilakukan pada tanah Inceptisol menggunakan biochar sampah organik $30 \mathrm{t}$ $\mathrm{ha}^{-1}$. Data yang dikumpulkan ditabulasi dan dianalisis dengan menggunakan analisis ekonomi usahatani. Hasil penelitian menunjukkan kombinasi aplikasi biochar dan pupuk kalium 1/4 dosis rekomendasi (perlakuan BK 1/4) secara ekonomis layak untuk dikembangkan petani ditinjau dari produksi $\left(7.02 \mathrm{t} \mathrm{ha}^{-1}\right)$, nilai jual (penerimaan) $\mathrm{Rp}$ 19.305.000 ha ${ }^{-1}$, pendapatan Rp 8.663.000 ha ${ }^{-1}$, kelayakan ekonomi (R/C) 1.8 dan nilai produktivitas tenaga kerja sebesar Rp 48.166/HKO.
\end{abstract}

Kata Kunci : Kelayakan ekonomi, usahatani jagung, biochar

\section{PENDAHULUAN}

Keberhasilan usahatani tidak hanya ditentukan berdasarkan faktor teknis budidaya dan rakitan teknologi yang tepat, akan tetapi kemauan dan kemampuan petani secara ekonomi juga berperan besar dalam mengkontribusi keberhasilan usahatani. Faktor yang sering menjadi kendala dalam pencapaian keberhasilan usahatani adalah kemampuan petani dalam membiayai usahatani. Faktor biaya sering menjadi faktor pembatas (limited factor/ budget constrain) dikarenakan ketersediaan biaya mempengaruhi kemampuan petani dalam penyediaan faktor produksi yang dibutuhkan dalam usahatani (Debertin, 1986 dan Widodo, 1988). Dalam kebijakan dan program Departemen Pertanian tahun 2008 disebutkan bahwa akar masalah pembangunan pertanian meliputi kepemilikan lahan, birokrasi 
di Deptan, modal, ketrampilan petani, teknologi, mentalitas petani, organisasi tani, petani, kebijakan, informasi, pemasaran dan tataniaga. Modal/biaya usahatani menjadi salah satu akar permasalahan yang menjadi perhatian untuk dipecahkan dan ikut menentukan arah kebijakan pertanian (www.deptan.go.id).

Biaya memang bukan satu-satunya permasalahan dalam usahatani, namun demikian ketersediaan biaya akan mempengaruhi permasalahan lain yaitu produksi yang rendah akibat minimnya faktor produksi yang digunakan petani disebabkan kurangnya biaya. Rendahnya produksi selanjutnya akan menyebabkan rendahnya nilai jual produk (revenue) dan bukan tidak mungkin produksi yang dihasilkan hanya cukup untuk kebutuhan konsumsi keluarga (subsistence) dan selanjutnya petani tidak bisa mencapai keuntungan atau kelayakan usaha secara ekonomi (Widodo, 1988; Hayami and Ruttan, 1971). Kondisi yang demikian akan mendorong petani menjadi tidak berdaya dan akan terus berlanjut jika tidak ada solusi yang tepat, sehingga mempengaruhi kemampuan dan kemauan petani untuk berusahatani pada musim tanam berikutnya. Secara teknis pemupukan merupakan upaya untuk meningkatkan hasil tanaman. Penggunaan pupuk anorganik dan organik dapat meningkatkan kesuburan tanah. Kesuburan tanah dengan curah hujan tinggi di daerah tropis bisa rendah karena bahan organik cepat mengalami mineralisasi (Jenkinson dan Ayanaba 1977). Kelemahan pupuk anorganik adalah aksesibilitas yang rendah bagi petani miskin (Garrity, 2004) dan efisiensi pemupukan rendah (Baligar dan Bennett, 1986). Disamping itu harga pupuk kalium yang relatif mahal menyebabkan pemborosan bila berlebihan dan mengganggu keseimbangan hara dalam tanah. Namun bila terlalu sedikit akan menimbulkan gejala kekurangan hara dan hasil maksimum tidak akan dicapai. Menurut Buckman dan Brady (1982), sebagian besar kalium yang diberikan dalam tanah akan terfiksasi di dalam ruang antar kisi liat dan hanya $1-2 \%$ yang dapat dimanfaatkan oleh tanaman. Sementara itu pupuk organik dapat meningkatkan efisiensi pemupukan. Pada daerah tropis pupuk organik cepat terdekomposisi. Sebaliknya karbon hitam (C) atau biochar jauh lebih stabil. Oleh karena itu perlu langkah strategis yang mengkombinasikan teknologi tepat guna, spesifik lokasi, sederhana dan biaya rendah untuk mengatasi permasalahan petani sekaligus meningkatkan produksi guna mendukung tercapainya tujuan pembangunan pertanian. Salah satu cara untuk mengatasi masalah kesuburan tanah dan ketersediaan kalium dengan menambahkan biochar. Banyak penelitian agronomi tentang aplikasi biochar yang telah dilakukan oleh peneliti sebelumnya, demikian juga penelitian tentang analisis kelayakan ekonomi usahatani di antaranya adalah penelitian Warsana (2007) tentang efisiensi dan keuntungan usahatani jagung, menyimpulkan bahwa usahatani jagung di Kecamatan Randublatung Kabupaten Blora kurang menguntungkan petani yang disebabkan naiknya harga faktor produksi yang berakibat pada peningkatan biaya usahatani. Ada perbedaan efisiensi antara petani dengan luas lahan di bawah 1 ha dengan 1 ha lebih, di mana petani dengan luas lahan di bawah 1 ha lebih efisien. Penelitian Supartama, Antara dan Rauf (2013) tentang analisis pendapatan dan kelayakan usahatani padi sawah di Subak Baturiti Desa Balinggi Kecamatan Balinggi Kabupaten Parigi Moutong menyimpulkan bahwa usahatani padi layak secara ekonomi yang ditunjukkan oleh pendapatan $\mathrm{Rp}$ 4.209.067,06/Ha/MT dengan nilai R/C 1,42, penelitian Sumantri, Priyono dan Isronita (2004) tentang kelayakan finansial usahatani lada dengan menggunakan data runtut waktu dan menyimpulkan bahwa usahatani lada di Desa Kunduran, Kecamatan Ulu Musi Kabupaten Lahat Layak secara ekonomi dengan NPV Rp 46.311.720, B/C 1,55 dan IRR $37,5 \%$. Penelitian lainnya dilakukan oleh Kurniawan (2005) tentang analisis kelayakan usahatani jerul siam pada lahan kering di Kecamatan Tapin Selatan Kabupaten Tapin Kalimantan Selatan dan menyimpulkan usahatani jeruk siam layak secara ekonomi pada beberapa tingkat discount factor (DF). NPV Rp 59.999.987 (DF 10\%), Rp 51.041.324 (DF 12\%), Rp 31.096.245 (DF 18\%) dan Rp 18.262.531 (DF 24\%). IRR 42,38\% dan payback period (PBP) tercapai pada tahun ke-6 (pada DF $10 \%, 12 \%$ dan $18 \%$ ), tercapai pada tahun ke-7 jika DF 24\%. Penelitian sosial ekonomi tentang aplikasi biochar pada petani masih sangat langka. Berdasarkan 
permasalahan yang telah disebutkan di atas, maka dilakukan penelitian yang bertujuan untuk mempelajari kelayakan ekonomi usahatani jagung dengan kombinasi aplikasi biochar dan pupuk kalium. Hasil penelitian ini diharapkan dapat meningkatkan efisiensi pemupukan kalium sehingga keuntungan usahatani dapat meningkat pula.

\section{METODE PENELITIAN}

Sebelum percobaan, terlebih dahulu membuat biochar dari sampah organik. Biochar diproduksi di Laboratorium Bioenergi Universitas Tribhuwana Tunggadewi. Bahan baku yang dijadikan biochar berupa sampah organik kota yang diambil dari UPTD Pengolahan Sampah Dinas Kebersihan Kota Malang. Pembuatan biochar dengan cara pirolysis. Biochar yang telah diproduksi, selanjutnya diaplikasikan ke lapangan sebanyak $30 \mathrm{t} \mathrm{ha}^{-1}$ dengan lama inkubasi 2 minggu. Rancangan percobaan dengan rancangan acak kelompok. Semua perlakuan diberi pupuk urea dan $\mathrm{SP}_{36}$ dengan dosis $90 \mathrm{~kg} \mathrm{~N} / \mathrm{ha}$ dan $100 \mathrm{~kg}$ $\mathrm{P}_{2} \mathrm{O}_{5} /$ ha. Pemupukan dilakukan pada umur 6 hari setelah tanam (hst), yaitu untuk $\mathrm{SP}_{36}$ dan $\mathrm{KCl}$, sedangkan urea diberikan dua kali. 1/3 bagian pada umur 6 hst dan $2 / 3$ bagian pada umur 30 hst. Pemupukan kalium diberikan saat 1 dan 4 mst sesuai dengan perlakuan yaitu kontrol, K1 (KCl $200 \mathrm{~kg} / \mathrm{ha}$ ), BK0 (biochar, tanpa $\mathrm{KCl}$ ), BK1/4 (biochar+KCl $50 \mathrm{~kg} \mathrm{ha}^{-1}$ $\mathrm{BK} 1 / 2$ (biochar+KCl $100 \mathrm{~kg} \mathrm{ha}{ }^{-1}$ ), BK3/4 (biochar+KCl $150 \quad \mathrm{~kg} \quad \mathrm{ha}^{-1}$ ), dan BK1 (biochar+KCl $200 \mathrm{~kg} \mathrm{ha}^{-1}$ ). Setiap perlakuan diulang tiga (3) kali. Petak percobaan sebanyak 21 plot dengan ukuran $3 \times 4 \mathrm{~m}^{2}$. Setelah inkubasi 2 minggu, dilakukan penanaman jagung varietas Bisi 12 sebagai tanaman indikator untuk mengukur perubahan kesuburan tanah sebagai fungsi pertumbuhan tanaman jagung dan hasil tanaman. Pemeliharaan tanaman dilakukan secara optimum. Jarak tanam jagung $80 \times 25 \mathrm{~cm}, 1$ tanaman dalam 1 lubang tanah sehingga populasi tanaman 50.000 tanaman $\mathrm{ha}^{-1}$. Tanaman jagung dibiarkan tumbuh sampai panen. Setelah panen juga dilakukan pengambilan sampel tanah untuk analisis sifatsifat tanah setelah perlakuan. Analisis sifat tanah meliputi bahan organik tanah (Walkey \& Black), N (Kjedahl), P tersedia (Bray 1), K tersedia (NH4OAC1N pH:7), $\mathrm{K}$ total $(\mathrm{HCl}$ $25 \%$ ) kapasitas penyimpanan air (pressure plate), tekstur tanah. Analisis tanaman dilakukan untuk tinggi tanaman, diameter batang (jangka sorong), luas daun (leaf area meter), bobot kering batang, daun, total tanaman di atas tanah, panjang dan diameter tongkol, bobot kering hasil jagung pipilan kering, kadar $\mathrm{K}$ tanaman $\left(\mathrm{HNO}_{3}+\mathrm{HClO}_{4}\right)$ dalam daun dan batang pada vegetatif maksimum dan dalam biji saat panen dan serapan hara K. Efisiensi pemupukan $\mathrm{K}$ dihitung dari kenaikan bobot kering hasil tanaman oleh pemberian setiap satuan bobot unsur hara $\mathrm{K}$ dalam bahan pupuk (Witt and Dobermann, 2006). Untuk mengukur efektivitas pupuk organik digunakan perhitungan Relative Agronomic Effectiveness (RAE) adalah perbandingan antara kenaikan hasil karena penggunaan suatu pupuk dengan kenaikan hasil dengan penggunaan pupuk standar dikalikan 100 (Ghosal et al., 2003). Pengamatan bobot kering dilakukan dengan mengeringkan bahan tanaman dalam oven pada suhu $70^{\circ} \mathrm{C}$ selama $2 \times 24 \mathrm{jam}$. Serapan hara K tanaman jagung ditentukan oleh bobot kering biomasa tanaman jagung dan kadar hara $\mathrm{K}$ dalam tanaman jagung. Data yang dikumpulkan dari hasil percobaan ditabulasikan dan dianalisis secara ekonomi dengan menggunakan analisis usahatani meliputi biaya produksi, penerimaan, pendapatan/keuntungan, kelayakan ekonomi dan produktifitas tenaga kerja.

\section{HASIL DAN PEMBAHASAN}

Usahatani jagung dengan dan tanpa biochar yang dikombinasi dengan pupuk kimia menunjukkan layak secara ekonomi (R/C 1.5 1.8). Biochar dan pupuk $\mathrm{K}$ dosis $50 \mathrm{~kg} \mathrm{ha}^{-1}$ (BK1/4) terbaik secara teknis dan ekonomis ditinjau dari produksi tanaman tinggi (7.02 $\mathrm{t}$ ha ${ }^{-}$ ${ }^{1}$ ), nilai jual (penerimaan) tertinggi $\mathrm{Rp}$ 19.305.000 ha $\mathrm{ha}^{-1}$, pendapatan tertinggi $\mathrm{Rp}$ 8.663 .000 ha $^{-1}$ dan kelayakan ekonomi (R/C) tertinggi 1.8 (Tabel 1). Penelitian yang dilakukan Woolf (2008) menilai dampak agronomi dan biaya usahatani dengan aplikasi biochar ke dalam tanah pada berbagai dosis. Secara teknis mudah diterapkan petani, mengurangi penggunaan dosis pupuk $\mathrm{K}$, menekan biaya produksi, dan membantu 
mengatasi permasalahan kelangkaan pupuk anorganik, instalasi produksi biochar sangat sederhana, kemudahan proses produksi dan aplikasi biochar pada lahan usahatani, ketersediaan bahan baku yang melimpah di sekitar petani, serta memanfaatkan limbah pertanian yang terbuang sia-sia. Nilai penggunaan tenaga kerja yang produktif karena upah yang dibayarkan lebih rendah dibanding kontribusi tenaga kerja pada usahatani. Produktivitas tenaga kerja tertinggi diperoleh pada perlakuan tanpa biochar dan hanya menggunakan pupuk anorganik (K1).

Produktivitas berdasarkan penerimaan dan produksi masing-masing sebesar $\mathrm{Rp}$ 82.139/HKO dan $29.87 \mathrm{~kg} / \mathrm{HKO}$ dengan upah kerja sebesar Rp 30.000/HKO (di bawah nilai produktivitas). Hal tersebut karena ada perbedaan curahan penggunaan tenaga kerja, yaitu $182.8 \mathrm{HKO} \mathrm{ha}^{-1}$ (tanpa biochar) dan 400.8 $\mathrm{HKO}$ ha $^{-1}$ (dengan biochar). Tingginya curahan tenaga kerja pada usahatani dengan biochar karena diperlukan penyediaan sarana dan proses pembuatan biochar pada tahun pertama. Biaya aplikasi biochar untuk tanah pertanian oleh Williams et al., (2010) disebutkan bahwa aplikasi biochar dengan cara larikan pada tingkat $2.5,5,10,25,50 \mathrm{t} \mathrm{ha}^{-1}$ dengan biaya masing-masing \$29, \$44, \$72, \$158, \$300 ha ${ }^{-1}$. Biaya tergantung beberapa variabel termasuk dosis, tingkat kedalaman parit, dan efisiensi operator. Pada dosis biochar 5, 10, 25, 50, $75 \mathrm{t}$ ha-1 dengan parit sedalam $2 \mathrm{~m}$ dan penggalian pada tingkat 15 per menit per hektar masingmasing sebesar \$34, \$85, \$171, \$341, dan $\$ 512$. Produksi tertinggi pada perlakuan 3 dengan kombinasi aplikasi biochar dan dosis pemupukan N, P sesuai rekomendasi dan dosis K 1/4 dari rekomendasi, sedangkan produksi terendah pada perlakuan 1 tanpa aplikasi biochar dengan dosis pemupukan $\mathrm{N}, \mathrm{P}$ dan $\mathrm{K}$ sesuai rekomendasi.

Tabel 1. Rekapitulasi Produksi, Biaya Usahatani, Harga Jual Produk, Penerimaan, Pendapatan dan Kelayakan Ekonomi Usahatani Jagung dengan Biochar dan Dosis Pupuk Kalium

\begin{tabular}{|c|c|c|c|c|c|c|c|c|c|}
\hline $\begin{array}{l}\text { Perla } \\
\text { kuan }\end{array}$ & $\begin{array}{l}\text { Produk } \\
\text { si } \\
\text { (ton/ha) }\end{array}$ & $\begin{array}{l}\text { Penggn } \\
\text {.T. } \\
\text { Kerja } \\
(\mathrm{HKO})\end{array}$ & $\begin{array}{l}\text { Biaya } \\
\text { Produksi } \\
(\mathrm{Rp} / \mathrm{ha}) \\
(000)\end{array}$ & $\begin{array}{l}\text { Harga } \\
\text { Jual } \\
\text { Produk } \\
(\mathrm{Rp} / \mathrm{kg})\end{array}$ & $\begin{array}{l}\text { Revenue } \\
\text { (Rp/ha) } \\
(000)\end{array}$ & $\begin{array}{l}\text { Pendap } \\
\text { atan } \\
(\mathrm{Rp} / \mathrm{ha}) \\
(000)\end{array}$ & $\begin{array}{l}\text { Kelay } \\
\text { akan } \\
\text { Ekon } \\
\text { omi } \\
(\mathrm{R} / \mathrm{C})\end{array}$ & $\begin{array}{l}\text { Produktiv } \\
\text { T. Kerja } \\
\text { (Rp/ } \\
\text { HKO) }\end{array}$ & $\begin{array}{l}\text { Produkti } \\
\text { v T. } \\
\text { Kerja } \\
(\mathrm{kg} / \\
\mathrm{HKO})\end{array}$ \\
\hline $\mathrm{K}_{1}$ & 5,46 & 182,8 & 8.405 & 2.750 & 15.015 & 6.610 & 1,8 & 82.139 & 29,87 \\
\hline $\mathrm{BK}_{0}$ & 6,24 & 400,8 & 10.417 & 2.750 & 17.160 & 6.743 & 1,6 & 42.814 & 15,57 \\
\hline $\mathrm{BK}_{1 / 4}$ & 7,02 & 400,8 & 10.642 & 2.750 & 19.305 & 8.663 & 1,8 & 48.166 & 17,51 \\
\hline $\mathrm{BK}_{1 / 2}$ & 5,78 & 400,8 & 10.867 & 2.750 & 15.895 & 5.028 & 1,5 & 39.658 & 14,42 \\
\hline $\mathrm{BK}_{3 / 4}$ & 6,26 & 400,8 & 11.092 & 2.750 & 17.215 & 6.123 & 1,6 & 42.952 & 15,62 \\
\hline $\mathrm{BK}_{1}$ & 6,57 & 400,8 & 11.317 & 2.750 & $18.067,5$ & $6.750,5$ & 1,6 & 45.079 & 16,39 \\
\hline
\end{tabular}

Sumber : Data primer hasil penelitian, diolah.

Tabel 2. Produksi Jagung dengan Aplikasi Biochar 6 Perlakuan 3 Ulangan.

\begin{tabular}{lrrrr}
\hline \multirow{2}{*}{ Perlakuan } & \multicolumn{3}{c}{ Ulangan (ton/ha) } & \multicolumn{2}{c}{ Rata-rata (ton/ha) } \\
\cline { 2 - 4 } & \multicolumn{1}{c}{ I } & II & III & \\
\hline NPK rekomendasi & 5,75 & 5,20 & 5,42 & 5,46 \\
BK0 & 6,69 & 6,17 & 5,86 & 6,24 \\
BK1/4 & 8,44 & 6,28 & 6,34 & 7,02 \\
BK1/2 & 5,84 & 5,59 & 5,93 & 5,78 \\
BK3/4 & 7,24 & 5,70 & 5,83 & 6,26 \\
BK1 & 6,25 & 6,70 & 6,74 & 6,57 \\
\hline
\end{tabular}

Sumber : Data primer hasil penelitian, diolah. 
Asnah dan Widowati : Kelayakan ekonomi usahatani jagung...

Tabel 3. Rata-rata Biaya Produksi Usahatani Jagung dengan Aplikasi Biochar, tanpa pupuk kimia.

\begin{tabular}{|c|c|c|c|c|}
\hline Uraian Biaya & $\begin{array}{l}\text { Jumlah per } \\
\text { skala } \\
\text { penelitian }\end{array}$ & $\begin{array}{l}\text { Jumlah } \\
\text { per } \\
\text { hektar }\end{array}$ & $\begin{array}{l}\text { Biaya } \\
\text { (Rp/skala } \\
\text { penelitian) }\end{array}$ & $\begin{array}{l}\text { Biaya } \\
\text { (Rp/hektar) }\end{array}$ \\
\hline $\begin{array}{l}\text { Tenaga kerja persiapan bahan baku } \\
\text { pembuatan instalasi biochar } \\
\text { 30.000/HKO }\end{array}$ & 5,5 & 22 & 165.000 & 660.000 \\
\hline $\begin{array}{l}\text { Tenaga kerja produksi biochar } 8 \text { periode } \\
\text { produksi, } 4 \text { HKO sekali produksi } @ \text { Rp } \\
\text { 15.000/HKO }\end{array}$ & 32 & 128 & 480.000 & 1.920 .000 \\
\hline $\begin{array}{l}\text { Kemasan bahan baku biochar dan biochar jadi } \\
\text { @ Rp } 500 / \text { buah }\end{array}$ & 16 & 64 & 8.000 & 32.000 \\
\hline $\begin{array}{l}\text { Transportasi bahan baku ke lokasi produksi } \\
\text { biochar menggunakan mobil pick up (kali) @ } \\
\text { Rp } 75.000\end{array}$ & 1 & 4 & 75.000 & 300.000 \\
\hline $\begin{array}{l}\text { Tenaga kerja Pengolahan Tanah sampai siap } \\
\text { tanam16,7 HKO@ Rp } 30.000\end{array}$ & 16,7 & 66,8 & 500.000 & 2.000 .000 \\
\hline Tenaga kerja Penanaman@ Rp 30.000 & 2 & 8 & 60.000 & 240.000 \\
\hline $\begin{array}{l}\text { Tenaga Kerja Pemeliharaan (pemupukan) @ } \\
\text { Rp 30.000/ HKO }\end{array}$ & 6 & 24 & 180.000 & 720.000 \\
\hline $\begin{array}{l}\text { Tenaga kerja Panen } 3 \text { orang } 1 \text { hari @ Rp } \\
\text { 30.000/HKO }\end{array}$ & 3 & 12 & 90.000 & 360.000 \\
\hline $\begin{array}{l}\text { Tenaga kerja pasca panen (menjemur) } 3 \text { hari } 2 \\
\text { orang @ Rp } 30.000\end{array}$ & 6 & 24 & 180.000 & 720.000 \\
\hline $\begin{array}{l}\text { Tenaga kerja pasca panen (memipil) @ Rp } \\
30.000 \text {, selama } 4 \text { hari } 3 \text { orang }\end{array}$ & 12 & 48 & 360.000 & 1.440 .000 \\
\hline Benih @ Rp 45.000 (kg) & 0,5 & 25 & 25.000 & 1.125 .000 \\
\hline Total Kebutuhan & & & 2.123 .000 & 8.517 .000 \\
\hline
\end{tabular}

Sumber : Data primer hasil penelitian, diolah.

Kenyataan tersebut menunjukkan bahwa aplikasi biochar mampu meningkatkan produksi jagung.

Secara ekonomi kebutuhan biaya pada usahatani jagung dengan aplikasi biochar tanpa pupuk kimia sebesar Rp 8.517.000 ha $\mathrm{h}^{-1}$, dengan komponen biaya terbesar pada biaya tenaga kerja pengolahan tanah sampai siap ditanami dan terendah biaya kemasan bahan baku dan produk jadi biochar. Secara umum pada perlakuan ini biaya terbesar pada biaya tenaga kerja. Biaya tenaga kerja pada produksi biochar tinggi hanya pada awal proses, setelah beberapa kali proses biaya akan secara langsung berkurang karena instalasi sudah ada dan juga dimungkinkan tingkat keberhasilan lebih tinggi karena telah terbiasa memproduksi biochar. Pada perlakuan ini rata-rata biaya yang dibutuhkan sebesar Rp 8.405.000 ha ${ }^{-1}$ dengan komponen biaya terbesar tetap pada biaya tenaga kerja. Tenaga kerja pada usahatani jagung baik dengan aplikasi biochar maupun tanpa aplikasi biochar dibutuhkan pada setiap tahap usahatani mulai persiapan lahan, persiapan sarana produksi, penanaman, pemeliharaan, panen sampai pasca panen. Oleh karena itu dilihat dari segi kebutuhan fisik maupun biaya tergolong besar. Kebutuhan biaya pada usahatani jagung dengan kombinasi aplikasi biochar dan pupuk kimia berbeda dengan perlakuan tanpa aplikasi biochar tapi tetap menggunakan pupuk kimia. 
Asnah dan Widowati : Kelayakan ekonomi usahatani jagung...

Tabel 4. Rata-rata biaya produksi usahatani jagung dengan menggunakan pupuk kimia tanpa biochar .

\begin{tabular}{|c|c|c|c|c|}
\hline Uraian Biaya & $\begin{array}{l}\text { Jumlah Per } \\
\text { skala } \\
\text { penelitian }\end{array}$ & $\begin{array}{l}\text { Jumlah } \\
\text { Per } \\
\text { hektar }\end{array}$ & $\begin{array}{l}\text { Biaya Per } \\
\text { skala } \\
\text { penelitian } \\
(\mathrm{Rp})\end{array}$ & $\begin{array}{l}\text { Biaya Per } \\
\text { hektar (Rp) }\end{array}$ \\
\hline Kebutuhan Pupuk KCL (kg)@ Rp 4.500/kg & 50 & 200 & 225.000 & 900.000 \\
\hline Kebutuhan Pupuk Urea (kg)@Rp 2.500 & 50 & 200 & 125.000 & 500.000 \\
\hline Kebutuhan Pupuk SP-36 (kg)@Rp 4.000 & 25 & 100 & 100.000 & 400.000 \\
\hline $\begin{array}{l}\text { Biaya Tenaga Kerja pengolahan tanah sampai } \\
\text { siap tanam } 16,7 \text { HKO @ Rp } 30.000\end{array}$ & 16,7 & 66,8 & 500.000 & 2.000 .000 \\
\hline Tenaga kerja penanaman@ Rp 30.000 & 2 & 8 & 60.000 & 240.000 \\
\hline $\begin{array}{l}\text { Tenaga kerja pemeliharaan (pemupukan)@ } \\
\text { Rp 30.000/HKO }\end{array}$ & 6 & 24 & 180.000 & 720.000 \\
\hline $\begin{array}{l}\text { Tenaga kerja panen } 3 \text { orang } 1 \text { hari @ Rp } \\
30.000 / \mathrm{HKO}\end{array}$ & 3 & 12 & 90.000 & 360.000 \\
\hline $\begin{array}{l}\text { Tenaga kerja Pasca panen (menjemur) } 3 \text { hari } 2 \\
\text { orang @ Rp } 30.000\end{array}$ & 6 & 24 & 180.000 & 720.000 \\
\hline $\begin{array}{l}\text { Tenaga kerja pasca panen (memipil)@ Rp } \\
30.000 \text {, selama } 4 \text { hari } 3 \text { orang }\end{array}$ & 12 & 48 & 360.000 & 1.440 .000 \\
\hline Benih@Rp $45.000(\mathrm{~kg})$ & 0,5 & 25 & 25.000 & 1.125 .000 \\
\hline Total Kebutuhan Biaya & & & 1.845 .000 & 8.405 .000 \\
\hline
\end{tabular}

Sumber : Data primer hasil penelitian, diolah.

Tabel 5. Perbedaan Biaya Usahatani Jagung Tanpa Biochar dan dengan Biochar.

\begin{tabular}{|c|c|c|}
\hline Uraian & $\begin{array}{l}\text { Kebutuhan Biaya per } \\
\text { skala penelitian (Rp) }\end{array}$ & $\begin{array}{l}\text { Kebutuhan Biaya Per } \\
\text { hektar (Rp/ha) }\end{array}$ \\
\hline $\begin{array}{l}\text { Biaya usahatani jagung tanpa biochar dan } \\
\text { pemupukan N,P,K sesuai rekomendasi }\end{array}$ & 1.845 .000 & 8.405 .000 \\
\hline $\begin{array}{l}\text { Biaya usahatani jagung dengan biochar dan } \\
\text { pemupukan N,P,sesuai rekomendasi tanpa pupuk K }\end{array}$ & 2.078 .000 & 10.417 .000 \\
\hline $\begin{array}{l}\text { Biaya usahatani jagung dengan biochar dan } \\
\text { pemupukan N,P,sesuai rekomendasi dosis K } 0,25 \\
\text { dari rekomendasi }\end{array}$ & 2.134 .250 & 10.642 .000 \\
\hline $\begin{array}{l}\text { Biaya usahatani jagung dengan biochar dan } \\
\text { pemupukan N,P,sesuai rekomendasi dosis K } 0,5 \\
\text { dari rekomendasi }\end{array}$ & 2.190 .500 & 10.867 .000 \\
\hline $\begin{array}{l}\text { Biaya usahatani jagung dengan biochar dan } \\
\text { pemupukan N,P,sesuai rekomendasi dosis K } 0,75 \\
\text { dari rekomendasi }\end{array}$ & 2.246 .750 & 11.092 .000 \\
\hline $\begin{array}{l}\text { Biaya usahatani jagung dengan biochar dan } \\
\text { pemupukan N,P, K sesuai rekomendasi }\end{array}$ & 2.303 .000 & 11.317 .000 \\
\hline
\end{tabular}

Biaya usahatani tertinggi pada usahatani jagung dengan aplikasi biochar dan pemupukan $\mathrm{N}, \mathrm{P}$, $\mathrm{K}$ sesuai rekomendasi, sedangkan biaya terendah pada usahatani jagung tanpa aplikasi biochar dan dengan aplikasi pupuk N, P, K sesuai rekomendasi. Hal ini disebabkan adanya perbedaan pada komponen biaya produksi biochar. 


\section{KESIMPULAN}

Usahatani jagung dengan dan tanpa biochar yang dikombinasi dengan pupuk kimia menunjukkan layak secara ekonomi dengan $R / C 1.5-1.8$. Kombinasi biochar dan pupuk $\mathrm{K}$ dosis $50 \mathrm{~kg} \mathrm{ha}^{-1}$ (perlakuan $\mathrm{BK}_{1 / 4}$ ) terbaik secara teknis dan ekonomis ditinjau dari produksi tertinggi $7.02 \mathrm{t} \mathrm{ha}^{-1}$, nilai jual (revenue) tertinggi $\mathrm{Rp} \quad 19.305 .000 \mathrm{ha}^{-1}$, pendapatan tertinggi $\mathrm{Rp} 8.663 .000 \mathrm{ha}^{-1}$ dan kelayakan ekonomi $(R / C)$ tertinggi 1.8 . penggunaan tenaga kerja produktif dengan nilai produktivitas berdasarkan penerimaan sebesar $\mathrm{Rp}$ 48.166/HKO dan berdasarkan produk 17.51 $\mathrm{kg} / \mathrm{HKO}$, dengan upah kerja sebesar $\mathrm{Rp}$ $30.000 / \mathrm{HKO}$.

\section{DAFTAR PUSTAKA}

Anonymous, 2008. Program Pembangunan Pertanian 2008-2013. www.deptan.go.id

Baligar V.C., Bennett O.L. 1986. Outlook on fertilizer use efficiency in the tropics. Fertil Res 10:83-96.

Buckman H. O. and N. C. Brandy. 1982. Soil Science. Bhratara Karya Aksara. Jakarta. p 721.

Debertin, David L, 1986. Agricultural Production Economics. Macmillan Publishing Company. New York and Collier Macmillan Publishers. London. P 299

Garrity D.P. 2004. Agroforestry and the achievement of the millenium development goals. Agroforest Syst 61:5-17.

Ghosal P.K., T. Chakraborty B. Bhattacharya D.K. Bagchi. 2003. Relative Agronomic Effectiveness of phosphate rocks and $\mathrm{P}$ adsorption characteristics of an Oxic Rhodustalf in Eastern India. J. Plant Nutr. Soil Sci. 166 (6): 750-755.

Hayami, Yojiro and Vernon Ruttan. 1971. Agricultural Development, An International Perspective. John Hopkins University Press. Baltimore and London.
Jenkinson D.S, Ayanaba A. 1977. Decomposition of carbon-14 labeled plant material under tropical conditions. Soil Sci Soc Am J 41:912-915.

Kurniawan, Ahmad Yousuf. 2005. Analisis Kelayakan Usahatani Jeruk Siam Pada Lahan Kering di Kecamatan Tapin Selatan Kalimantan Selatan. Jurnal Ziraa'ah 12 (1) : 12-17.

Sumantri, Bambang, Basuki Sigit Priyono dan Mery Isronita. 2004. Analisis Kelayakan Finansial Usahatani Lada di Desa Kunduran Kecamatan Ulu Musi Kabupaten Lahat Sumatera Selatan. Jurnal Ilmu-ilmu Pertanian Indonesia. 6 (1) : 3242.

Supartama, Made, Made Antara dan Rustam Abd. Rauf. 2013. Analisis Pendapatan dan Kelayakan Usahatani Padi Sawah di Subak Baturiti Desa Balinggi Kecamatan Balinggi Kabupaten Parigi Moutong. Ejurnal Agrotekbis 1 (2) : 166-172

Warsana. 2007. Analisis Efisiensi dan Keuntungan Usahatani Jagung Studi di Kecamatan Randublatung Kabupaten Blora. Thesis Univ. Diponegoro. Dipublikasikan dalam www.eprint.undip.ac.id/17660/1/warsana. pdf diakses 31 Mei 2015.

Witt C., J. M. Pasuquin., and A. Dobermann. 2006. To wards a site-specific nutrient management approach for maize in Asia. Better Crops 90 (2):28-31.

Widodo, Sri. 1988. Production Efficiency Of Rice Farmers in Java Indonesia. Gadjah Mada University Press. Yogyakarta. P 17.

Woolf, D. 2008. Biochar as a soil amendment: $A$ review of the environmental implications. Swansea University, UK. http://orgprints. org/13268/01/Biochar_as_a_soil_amendm ent_- _ a review.pdf. Accessed on May 4, 2010 . 